\title{
IMPACTO DO SISTEMA DE FORNECIMENTO AR/COMBUSTÍVEL NO DESENVOLVIMENTO DE CATALISADORES AUTOMOTIVOS
}

\author{
Nunes, L. ${ }^{1}$, Lima, W. ${ }^{1}$, Piccoli, R. ${ }^{1}$ e Zoca, M. ${ }^{1}$ \\ ${ }^{1}$ Umicore Brasil Ltda \\ lucas.nunes@am.umicore.com; walter.lima@am.umicore.com, \\ renan.piccoli@am.umicore.com; miguel.zoca@am.umicore.com
}

\section{RESUMO}

Nesse trabalho, as principais diferenças de características na definição de um projeto de catalisador automotivo para aplicações de motores turbo e natural aspirados são apresentadas. Catalisadores automotivos foram projetados e avaliados em dois veículos com o mesmo volume de motor, porém com alimentação de ar/combustível diferentes; natural aspirado com injeção de combustível indireta (NA / MPFI) e turbo alimentado com injeção direta de combustível (TC / DFI). Os veículos foram submetidos a ensaios de emissões conforme ciclos ABNT NBR 6601 e ABNT NBR 7024 (HWFE) [1]. Além das medições das emissões de gases brutas do motor, ou seja, gases gerados durante a combustão, e dos gases da saída do escapamento, pós catalisador envelhecido $80 \mathrm{k} \mathrm{km}$, para determinação da eficiência catalítica, a temperatura também foi mapeada, assim como a eficiência energética dos veículos.

Na tecnologia TC / FDI foi observado um ganho em eficiência energética, o que contribuiu para a redução da temperatura do gás do escapamento. Foi observado ainda um melhor controle na mistura ar / combustível e um perfil de temperatura mais estável o que favorece a uma maior durabilidade do catalisador.

$\mathrm{O}$ estudo demonstrou ainda que para o ideal dimensionamento dos catalisadores, como escolha do volume, tecnologia, etc., estas variáveis devem ser levadas em consideração, principalmente no que diz respeito ao light-off.

\section{INTRODUÇÃO}

Com a introdução do programa Inovar Auto, as montadoras implementaram várias soluções tecnológicas com o objeto de aumentar a eficiência energética dos veículos produzido no Brasil. Assim, para esse propósito, sistemas de turbo comprimido de alimentação de ar e injeção direta de combustíveis foram implementados, mudando o comportamento dos motores outrora equipados com sistemas aspirado para alimentação de ar e injeção indireta de combustível. Assim, a composição química e o perfil de temperatura dos gases de escapamento foral alterados [2]. Para essa nova realidade, sistemas de pós tratamento precisam ser redefinidos.

Vários fatores são importantes para a definição do modelo de catalisador a ser aplicado, entre eles o tempo de light off (tempo necessário para conversão de 50\% dos gases tóxicos), o qual está diretamente relacionado à composição e ao perfil de temperatura dos gases emitidos pelo motor, além da composição química do catalisador. 


\section{SISTEMAS DE ALIMENTAÇÃO AR/COMBUSTIVEL EM MOTORES OTTO FLEX}

\subsection{Os motores flex NA / MPFI}

No Sistema MPFI (Multi Port Fuel Injection) o gerenciamento digital permite utilizar estratégias no motor programadas na Unidade Central de Informações do Veículo (ECU).

A ECU considera as informações recebidas do sensor de oxigênio, que é feita por malha fechada, e a mesma é flexível à mistura de combustíveis. Outra informação relevante provém da medição de massa de ar, que é feita por vazão mássica ou por meio de pressão do coletor, pois cada condição de funcionamento do motor possui uma vazão de massa de ar admitido [3].

A injeção de combustível é feita fasada ao ponto morto superior do cilindro onde a quantidade de combustível é precisa e atualizada a cada evento da combustão (figura 01).

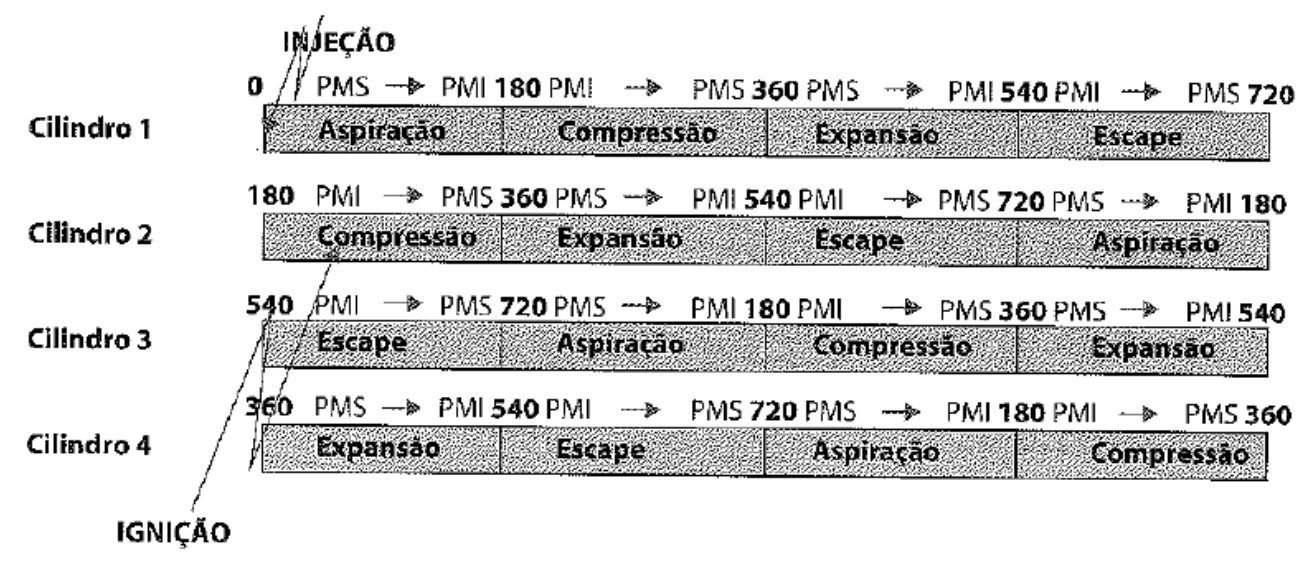

FIGURA 01: Esquema de sistema sequencial fasado [3]

Com os valores de massa de ar admitido e da injeção de quantidade de combustível, o sistema é realimentado por controle de malha fechada como apresentado na figura 02 . Com o sinal do sensor de oxigênio, a central eletrônica realiza as correções da massa de combustível injetada $[2,3]$.

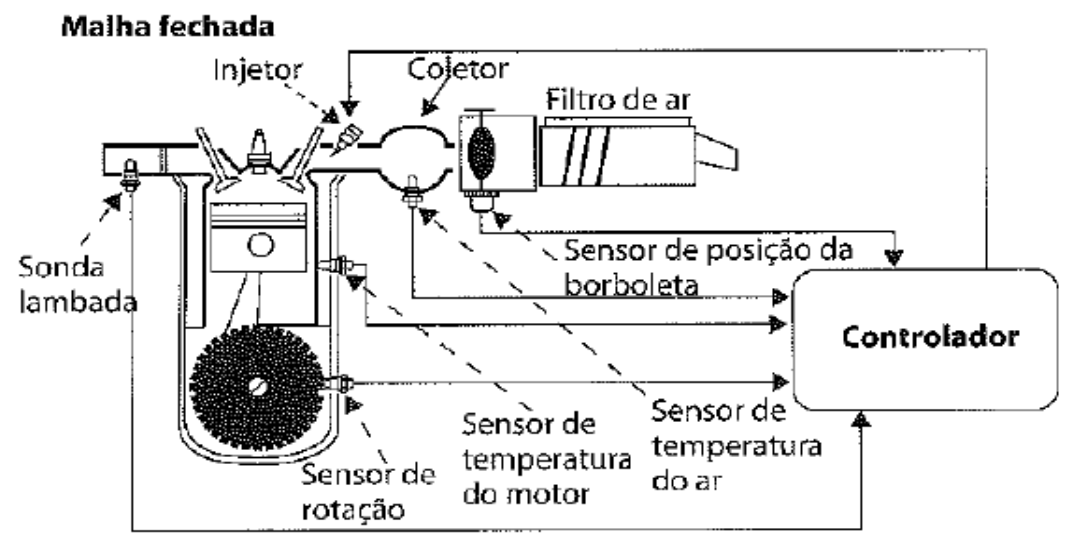

FIGURA 02: Controle em malha fechada [3] 
Cálculos de Dinâmica de Fluidos (CFD) são utilizados para estudar os fenômenos interno nos motores, como a melhor distribuição do spray de combustível, favorecendo a mistura de modo turbulento, para que o processo de queima seja mais rápido, havendo assim, uma melhor eficiência energética $[1,4,5]$.

Para emissões, essa dinâmica é fundamental na formação de gases de exaustão. Quando houver um equilíbrio na mistura, ou seja, a relação ar / combustível ideal, a mistura estequiométrica se comporta de modo equilibrado conforme a figura $03[4,6]$.

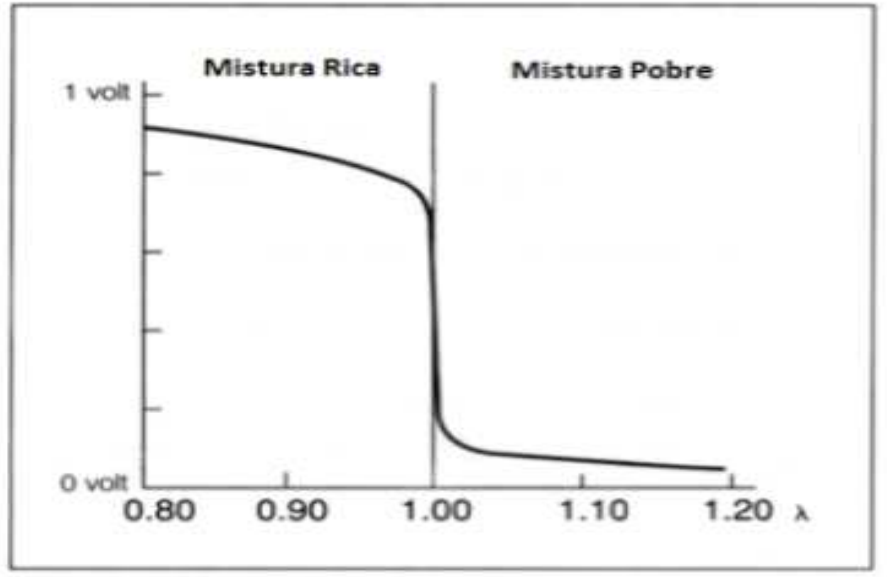

FIGURA 03: Relação ar combustível [6]

Para determinação do conversor catalítico em motores Otto, essa mistura é um dos fatores determinante. As tecnologias TWC (three way catalyst) são projetadas considerando a relação ar/combustível (lambda) próximo de 1.0 (ponto estequiométrico) [6].

Em valores de lambda abaixo de 1.0, a mistura é chamada de rica, onde há falta de oxigênio e ocorre a redução do NOx. Já para lambda acima de 1,0, a mistura é chamada de pobre, há excesso de oxigênio e ocorre a oxidação dos gases HC (hidrocarbonetos) e CO (monóxido de carbono). A figura 04 ilustra o processo de operação do TWC.

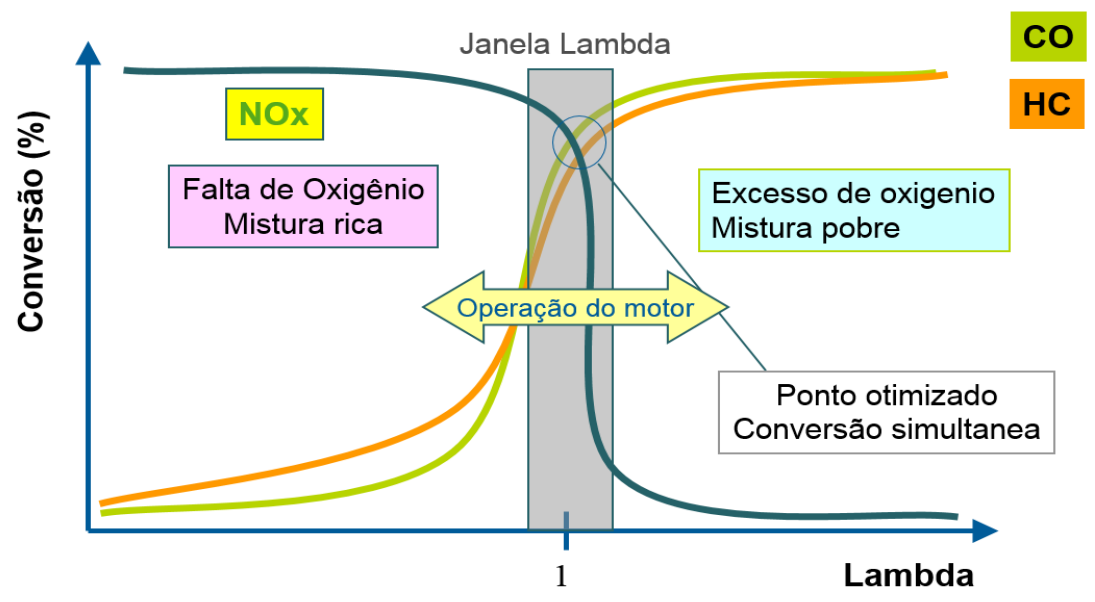

FIGURA 04: Processo de funcionamento do TWC em função do lambda (fonte UMICORE) 


\subsection{Os motores flex TC / FDI}

As aplicações de Turbo Compressor (TC) e Injeção Direta de Combustível (FDI) nos motores de ciclo Otto vem aumentando com o objetivo de atingir uma eficiência térmica semelhante à obtida em motores do ciclo Diesel [3].

O motor com TC alimentado pelo gás de escapamento, consiste de dois turboelementos; uma turbina e um compressor instalados em um único eixo. A turbina utiliza a energia do gás de escapamento para acionar o compressor. Já o compressor aspira o ar fresco que é fornecido aos cilindros sob forma comprimida[2, 3].

Geralmente, a sobrealimentação aumenta a eficiência de motores de combustão interna, os quais trabalham com relação ar combustível equilibrada favorecendo o melhor funcionamento dos catalisadores TWC na conversão dos gases tóxicos [3, 4].

Com a introdução da injeção direta, a turboalimentação se tornou uma perspectiva mais interessante, comparada a outros processos de sobrealimentação (figura 05).

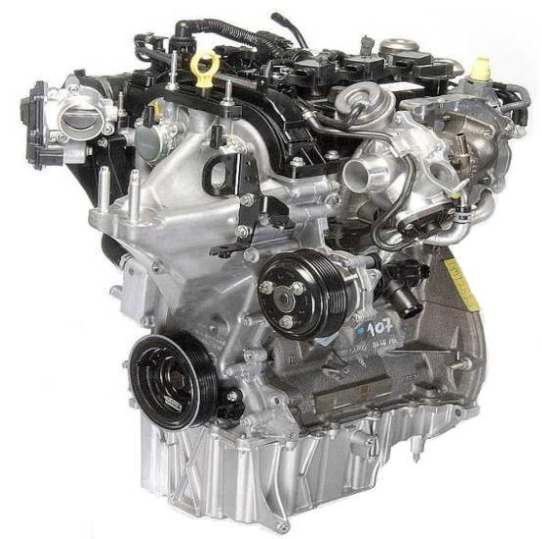

FIGURA 05: Motor turbo com injeção direta de combustível (Fonte: Desconhecido)

A principal diferença entre os sistemas de alimentação de combustível, comparando os sistemas de injeção direta e indireta, são os bicos injetores e a pressão de trabalho. Nos sistemas de injeção direta os bicos precisam suportar a pressão e a temperatura da câmara de combustão, com a devida capacidade de atomização do combustível. A pressão nos bicos injetores de FDI são maiores e o sistema trabalha com uma bomba de baixa pressão e um sistema secundário de bomba de alta pressão [2, 3].

No tubo de distribuição de combustível, a pressão é controlada através de sensores que permitem a correção do combustível. Esse controle é essencial para a partida do motor [2].

A definição de mistura, estratificada ou homogênea, varia conforme o desenho do motor associado às propriedades do combustível. O sistema de injeção direta permite a divisão da massa injetada de combustível (Figura 06). 

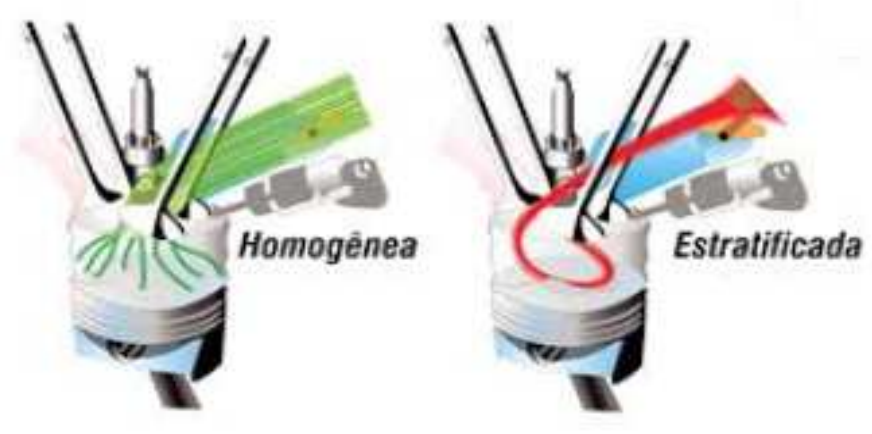

FIGURA 06: Injeção Homogêneo e Injeção Estratificada (Fonte: Desconhecido)

Destacam-se também as principais diferenças na partida a frio em regime transiente, onde ocorrem as maiores emissões de HC e CO. Nas acelerações e desaceleração a compensação de combustível é feita diretamente na câmara de combustão, que minimiza os erros de correção, garantindo a melhor qualidade da mistura.

Com combustão estratificada, essa operação aumenta a emissão de NOx. Uma tecnologia viável e bastante utilizada é a válvula de recirculação dos gases - EGR. O principal efeito desse sistema é a diluição parcial dos gases de admissão com os gases do escapamento originários da queima do combustível, que proporcionam um atraso no início da ignição, reduzindo a temperatura da chama, sendo este o principal agente na redução do NOx (Hawley, 1998 e Mellow, 1999) [2].

\section{PARÂMETROS PARA O DESENVOLVIMENTO DE CATALISADORES AUTOMOTIVOS}

No desenvolvimento de catalisadores automotivos alguns parâmetros são fundamentais, entre eles: a características do veículo, a temperatura do gás de escapamento, a relação ar combustível e as emissões brutas dos gases da combustão.

Cada veículo possui características únicas. Desta forma, informações do veículo devem ser conhecidas no desenvolvimento do catalisador para um dimensionamento correto no atendimento das necessidades. Um fator de relevância é o sistema de injeção de combustível, o qual determina a qualidade da mistura.

A temperatura do gás de escapamento é um dos parâmetros necessários para a ativação do catalisador [6]. Assim que conhecida, a tecnologia do catalisador é selecionada de forma criteriosa para que esta ativação ocorra no tempo hábil.

Nas aplicações "flex fuel" (gasolina e etanol), a temperatura tem perfis distintos dependendo do combustível utilizado, assim como a relação ar/combustível e as emissões brutas da combustão, as quais são essenciais para a definição do sistema de pós tratamento das emissões tóxicas. Os catalisadores, geralmente os de três vias, são dimensionados considerando esses fatores de modo a atender a legislação vigente imposta [7]. 


\section{METODOGIAS PARA AVALIAÇÃO DOS CATALISADORES E VEÍCULOS}

\subsection{ABNT NBR 6601}

Define-se conforme ABNT NBR 6601, o método para a determinação de hidrocarbonetos totais (THC) e não metano (NMHC), monóxido de carbono (CO), óxidos de nitrogênio (NOx), dióxido de carbono $(\mathrm{CO} 2)$ e material particulado emitidos pelo motor através do tubo de descarga de veículos rodoviários automotores leves, sob condições simuladas de uso normal médio em trânsito urbano.

Define-se também, as características mínimas dos equipamentos e materiais, bem como estabelece o ciclo de condução utilizado na execução dos ensaios.

Conforme a norma ABNT NRBR 6601, o ensaio é realizado para determinar a emissão em massa de hidrocarbonetos, monóxido de carbono e óxidos de nitrogênio, enquanto o veículo simula uma viagem média, em área urbana, com distância aproximada de $12,1 \mathrm{~km}$. $\mathrm{O}$ ensaio, em dinamômetro de chassi, consiste na partida do motor e na operação do veículo através de um ciclo de condução especificado. O ensaio completo em dinamômetro de chassi consiste em dois ciclos de aproximadamente $12,1 \mathrm{~km}$, sendo um com partida a frio e o outro com partida a quente, com intervalo de $10 \pm 1$ min entre eles. $\mathrm{O}$ resultado é a média ponderada entre os ciclos de partida a frio e a quente, que representa, assim, uma viagem padrão de aproximadamente $12,1 \mathrm{~km}$. O ensaio de partida a frio é dividido em dois períodos. O primeiro período, representando a fase "transitória" da partida a frio, termina ao final da desaceleração que é programada para ocorrer aos 505 s do ciclo de ensaio. O segundo período, representando a fase "estabilizada", consiste na conclusão do ciclo de ensaio, inclusive o desligamento do motor. Da mesma maneira, o ensaio de partida a quente consiste em dois períodos. O primeiro período, representando a fase "transitória", termina também com o final da desaceleração aos $505 \mathrm{~s}$, enquanto que o segundo período do ensaio de partida a quente, representando a fase "estabilizada" é idêntico ao segundo período do ensaio de partida a frio. Assim, o ensaio de partida a quente termina no final do primeiro período $(505 \mathrm{~s})$. O gás coletado do veículo é diluído em ar, de modo a se obter uma vazão total constante. Uma alíquota desta mistura é coletada também em vazão constante e armazenada para a análise conhecida como BAG [7].

\subsection{ABNT NBR 7024 (HWFE)}

Define-se conforme ABNT NBR 7024 o método para a medição do consumo de combustível de veículos rodoviários automotores leves, por meio de ciclos de condução desenvolvidos em dinamômetro de chassi, que simulam o uso do veículo no trânsito urbano, conforme NBR 6601, e de estrada. Com os dados de consumo, calcula-se a eficiência energética [7].

\section{PARTE EXPERIMENTAL}

Dois veículos, um equipado com motor NA / MPFI e outro com TC / MPFI, foram avaliados em dinamômetro de chassi, conforme metodologias descritas acima. Os catalisadores dos veículos foram previamente envelhecidos em dinamômetros de motores a $80.000 \mathrm{~km}$, conforme metodologia UMICORE. 


\section{RESULTADOS OBTIDOS E DISCUSSÃO}

\subsection{EMISSÕES BRUTAS, PERFIL DE TEMPERATURA DOS GASES NA SAÍDA DO MOTOR E LIGHT-OFF NO VEÍCULO EQUIPADO COM O MOTOR NA / MPFI}

Utilizando-se das metodologias descritas acima, o veículo com motor NA / MPFI foi avaliado no dinamômetro de chassi onde as emissões brutas foram determinadas, assim como os perfis de temperatura na saída do motor, nos combustíveis A22 e EHR (figura 07). Observou-se que o motor alimentado com EHR emitiu uma menor quantidade de poluentes para os três gases analisados.

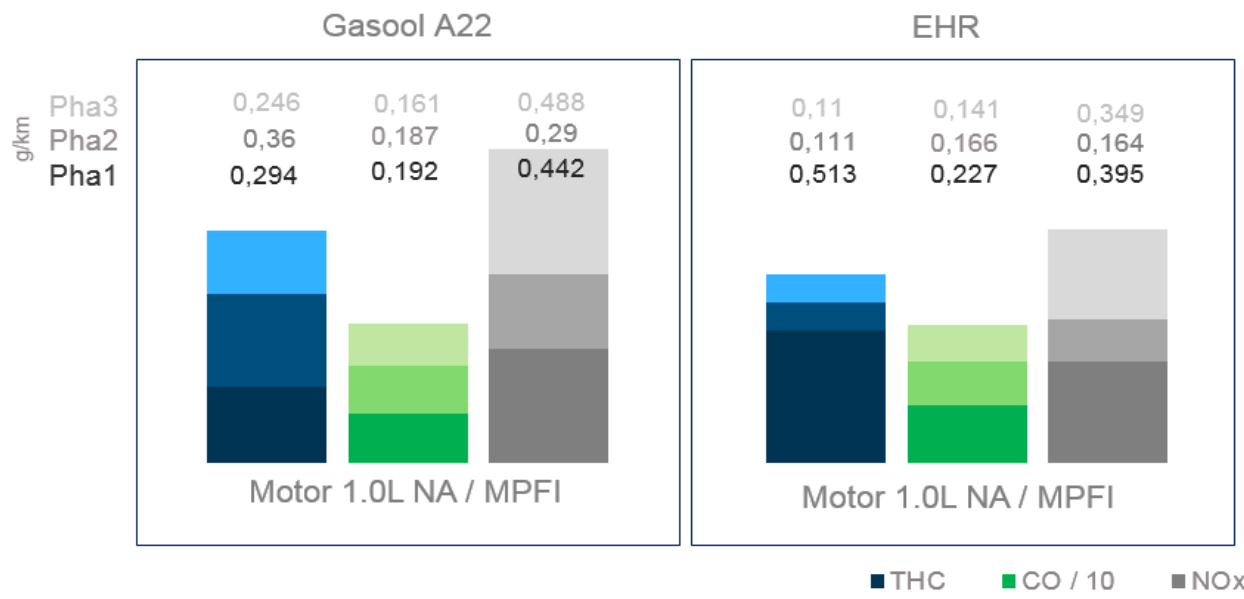

FIGURA 07 - Emissões brutas do motor NA/MPFI em g/km

$\mathrm{Na}$ determinação da temperatura do gás de escapamento antes da entrada do catalisador, observou-se que, entre os combustíveis, o A22 apresentou um maior valor que o encontrado com EHR (figura 08), principalmente no início do ciclo.
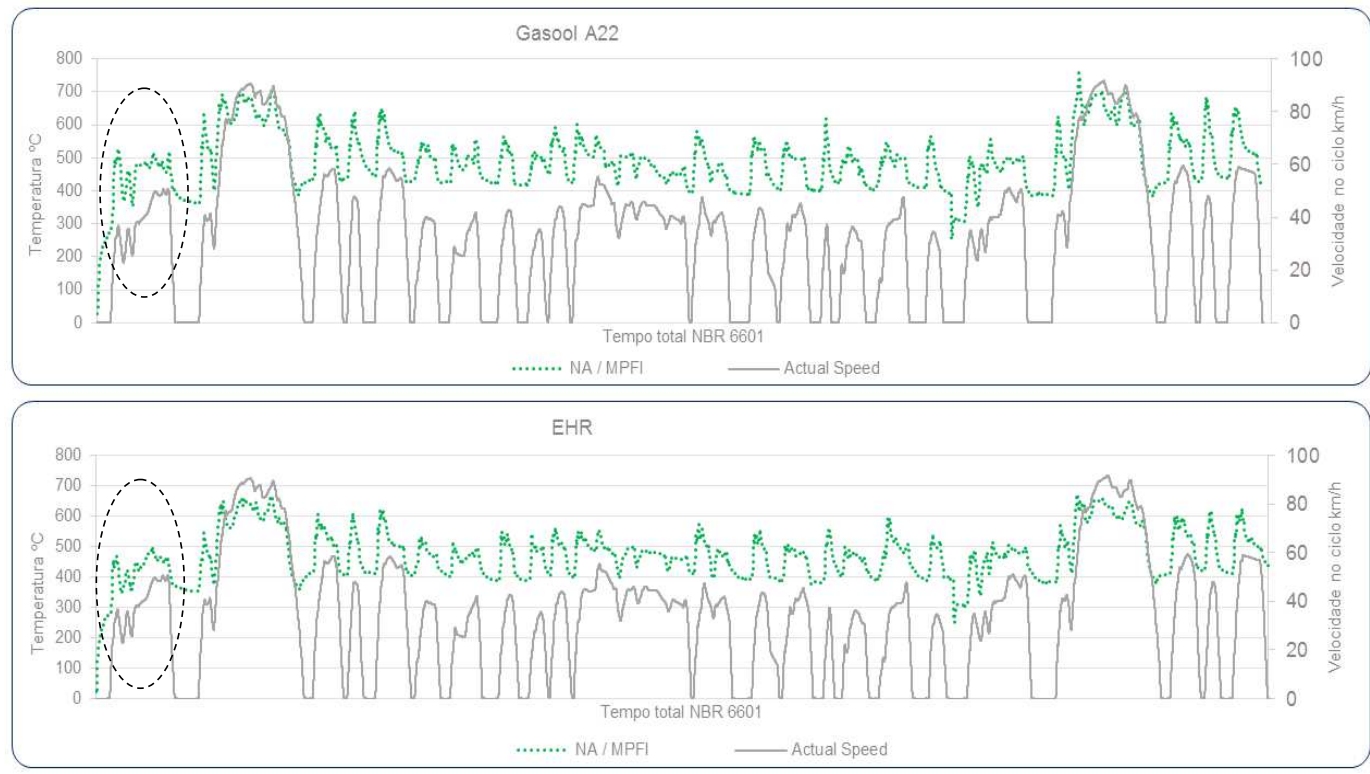

FIGURA 08 - Perfil de temperatura no motor NA/MPFI alimentados com A22 e EHR 
Um parâmetro importante no desenvolvimento de catalisadores é o seu tempo de lightoff (o tempo necessário para o catalisador atingir conversões de 50\% para os gases tóxico). Esse tempo é determinado após a estabilização térmica do catalisador, e quanto menor esse tempo melhor será a eficiência catalítica.

$\mathrm{Na}$ figura 09 é possível verificar os tempos de light-off para o catalisador. Com A22, o THC demorou 62s para atingir 50\% de conversão, o CO 68s e o NOx 76s.

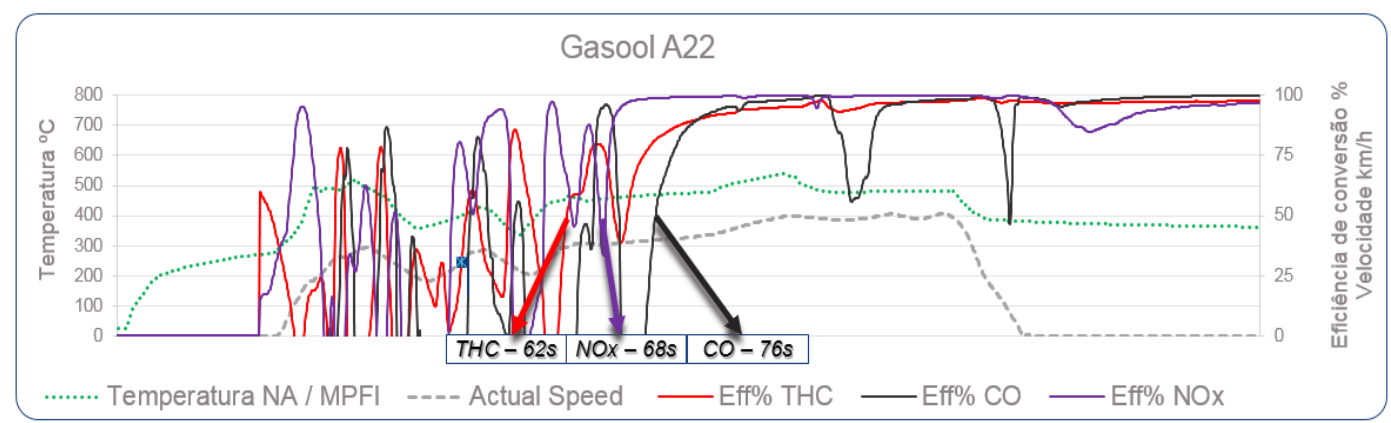

FIGURA 09 - Temperatura de light off do catalisador no motor NA/MPFI alimentado com A22

Com o EHR, o THC demorou 62s para atingir 50\% de conversão, CO 69s e o NOx 80s (figura 10).

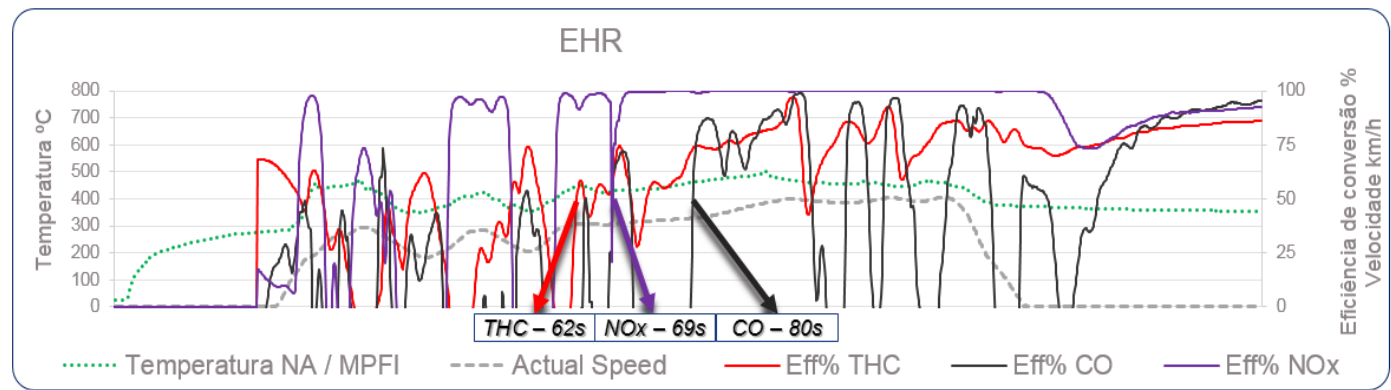

FIGURA 10 - Temperatura de light off do catalisador motor NA/MPFI alimentado com EHR

\subsection{EMISSÕES BRUTAS, PERFIL DE TEMPERATURA DOS GASES NA SAIIDA DO MOTOR E LIGHT-OFF NO VEÍCULO EQUIPADO COM O MOTOR TC / FDI}

Como realizado no item anterior, o veículo com motor TC / FDI foi avaliado no dinamômetro de chassi onde as emissões brutas foram determinadas (figura 11), assim como os perfis de temperatura na entrada do catalisador, para os combustíveis A22 e EHR (figura 12). 

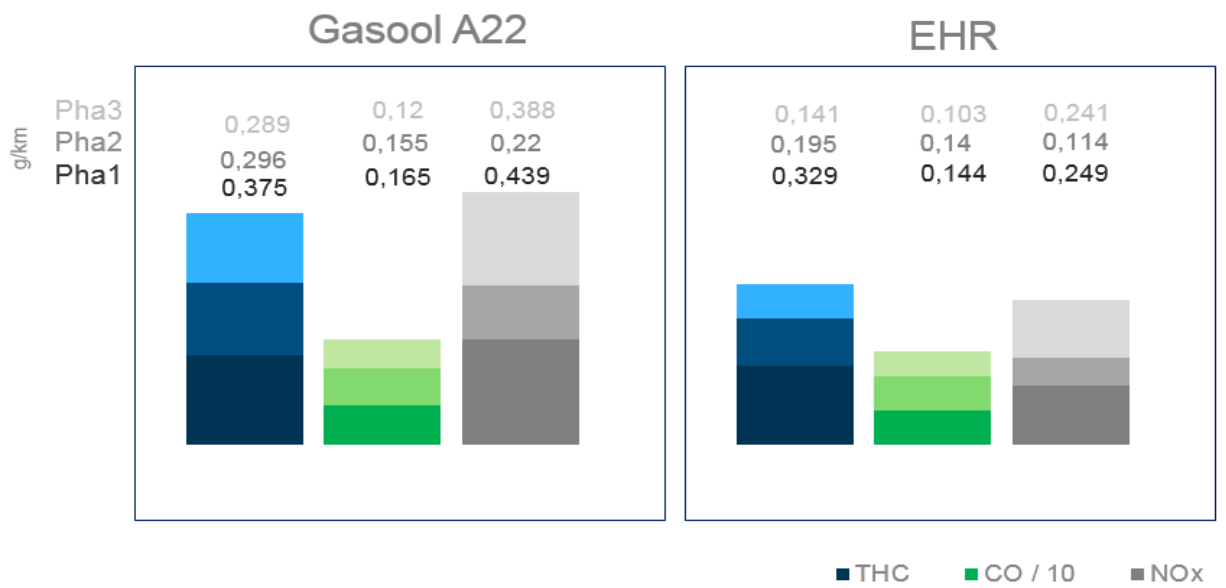

FIGURA 11 - Emissões brutas do motor TC/FDI em g/km

Assim como no veículo NA / MPFI, observa-se uma maior temperatura do gás de escapamento antes da entrada do catalisador para o A22 quando comparado com o EHR. Observa-se também que a temperatura do gás de escapamento no veículo de aplicação TC / FDI é mais estável, em ambos os combustíveis, favorecendo a uma maior durabilidade do catalisador. A quantidade de poluentes nos três gases emitidos pelo motor TC / FDI também foi menor no veículo alimentado com EHR.

Foi observado que independentemente do tipo de motor estudado, os motores alimentados com EHR geram emissões brutas menores de poluentes.
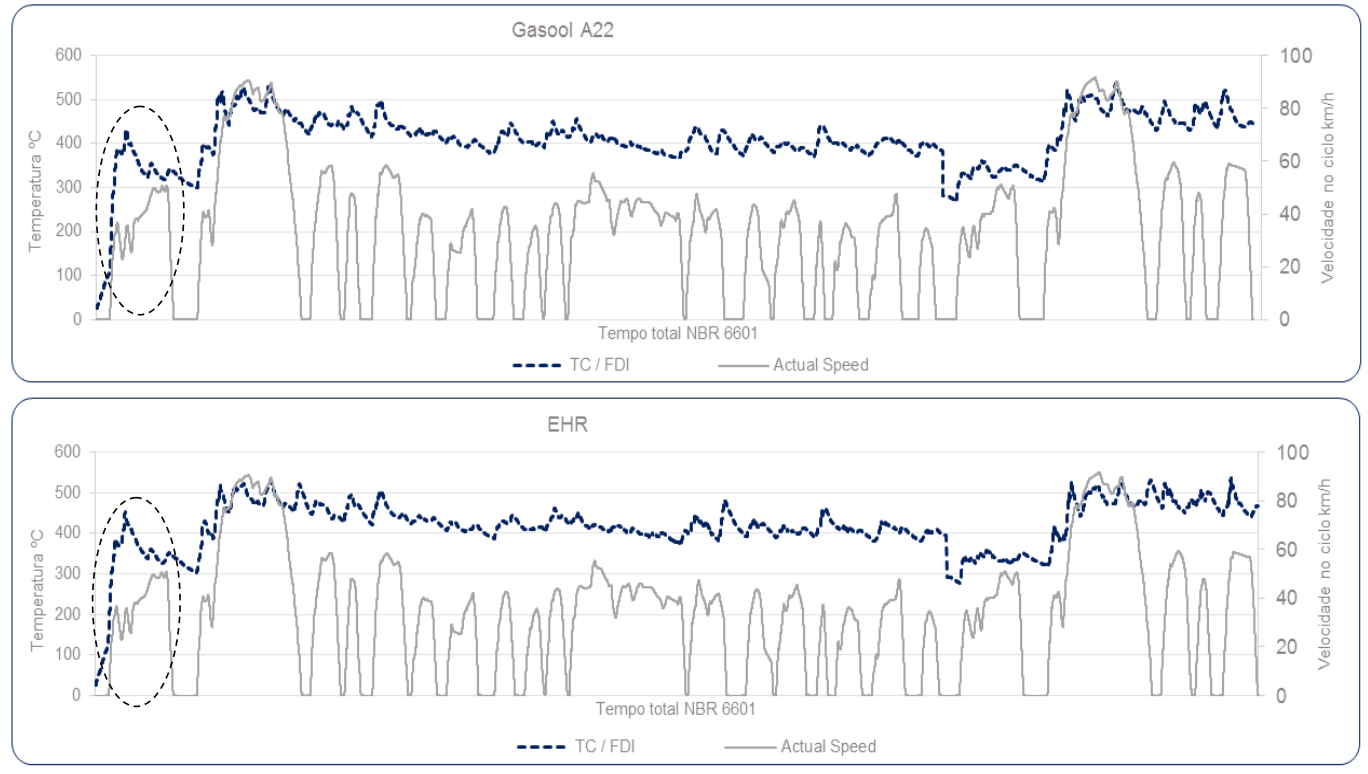

FIGURA 12 - Perfil de temperatura no motor TC/FDI alimentados com A22 e EHR

O veículo equipado com o motor TC / FDI também teve os tempos de light-off determinados para os três gases tóxicos nos dois combustíveis.

No A22, o THC demorou 48s para atingir 50\% de conversão, CO 59s e NOx 76s (figura 13). 


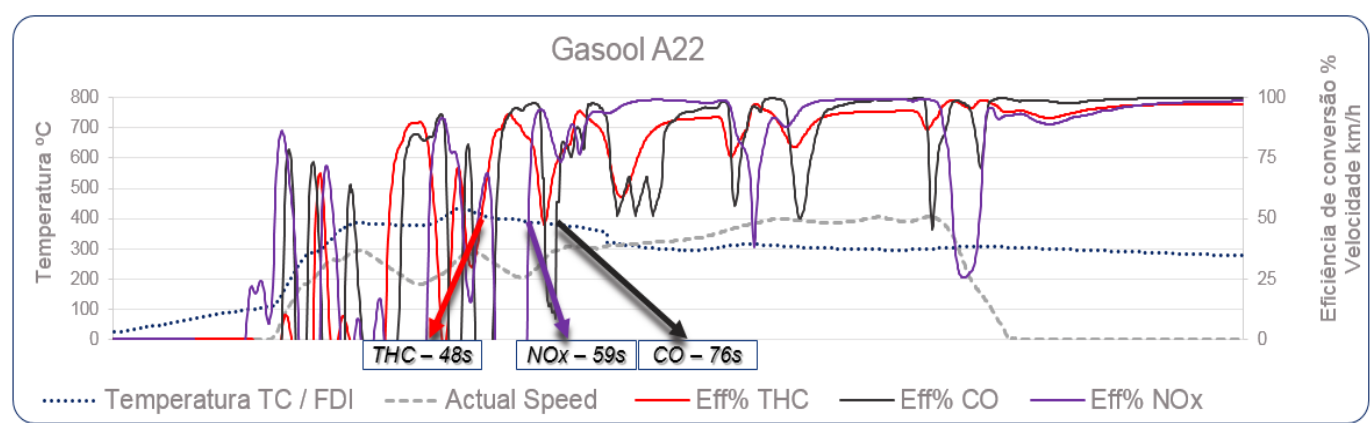

FIGURA 13 - Temperatura de light off do catalisador motor TC/FDI alimentado com A22;

No EHR, o THC e CO demoraram 46s para atingir 50\% de conversão e NOx 31s (figura 14).

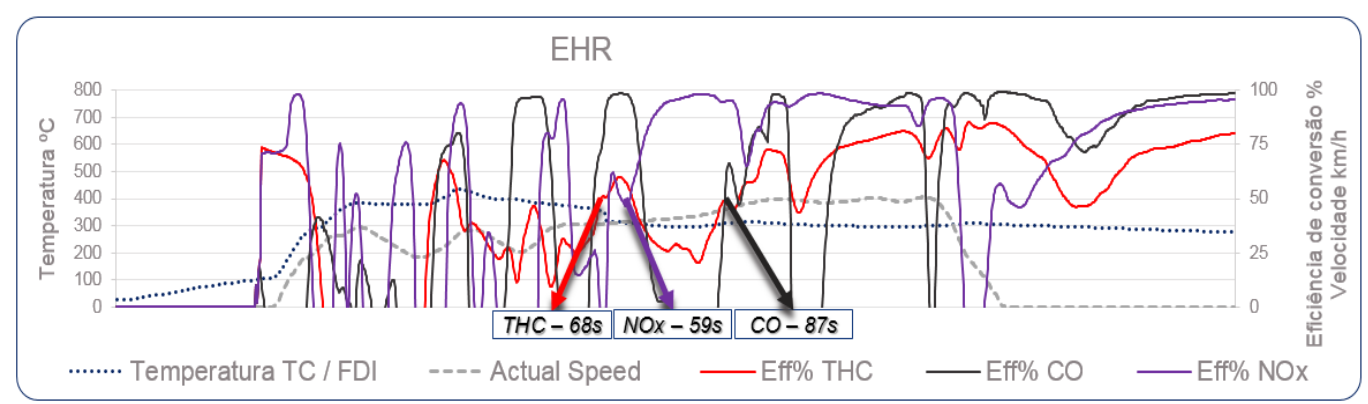

FIGURA 14 - Temperatura de light off do catalisador motor TC/FDI alimentado com EHR;

Desta forma, fica evidente que a primeira fase do ciclo NBR 6601 é a mais crítica para o tratamento das emissões, e consequentemente, para o desenvolvimento do catalisador. As emissões no período antes do light-off do catalisador não são convertidas, pois o catalisador ainda não tem temperatura suficiente para sua ativação térmica.

Comparando-se os dois tipos de motores estudados, NA / MPFI e TC / FDI, observase que o tempo de light-off do catalisador para todos os gases foram menores no motor TC / FDI em ambos os combustíveis, com exceção do NOx, cujos valores foram iguais nos dois motores alimentados com A22.

\subsection{RESULTADOS DAS EMISSÕES DEPOIS DO CATALISADOR CONFORME AS CARACTERISTICAS ORIGINAIS DOS VEÍCULOS.}

Através dos resultados observados nas emissões brutas e perfil de temperatura na entrada do catalisador, os mesmos foram projetados e avaliados. Os resultados das eficiências catalíticas nos dois combustíveis são apresentados na figura 15 . 

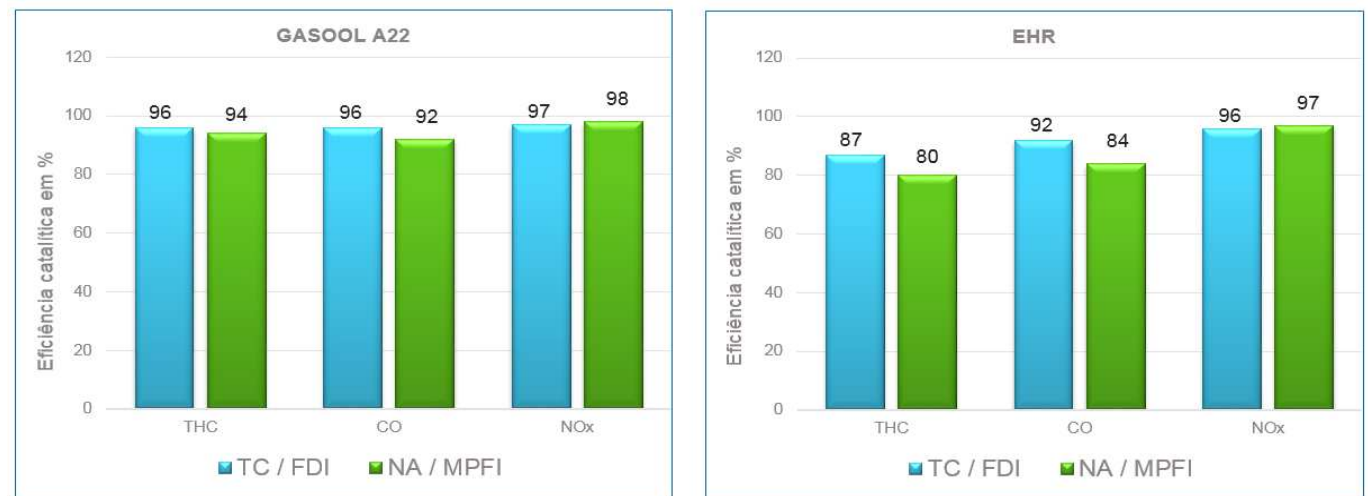

FIGURA 15 - Eficiência catalítica nos motores NA/MPFI e TC/FDI alimentados com A22 e EHR

Em ambos os veículos, os catalisadores foram projetados conforme as respectivas necessidades com o objetivo de atender aos limites de emissões da legislação vigente (PROCONVE L6).

Comparando-se os dois motores estudados, NA / MPFI e TC / FDI, observa-se que, para os dois combustíveis, o catalisador aplicado no motor TC / FDI tem uma melhor eficiência catalítica para os gases $\mathrm{HC}$ e $\mathrm{CO}$, enquanto que o NOx os valores foram equivalentes nos dois motores. Essa melhor eficiência catalítica ocorreu devido ao menor tempo de light-off observado no motor TC / FDI. Entretanto, com A22 as eficiências catalíticas nos dois veículos foram melhores do que com EHR, devido a maior temperatura no gás de escapamento na entrada do catalisador.

\subsection{ANALISE DA RELAÇÃO AR / COMBUSTÍVEL.}

Conforme descrito anteriormente, a primeira fase é a fase mais crítica na análise das emissões devido ao tempo de ativação térmica do catalisador.

Desta forma, observa-se o comportamento da mistura estequiométrica nos veículos NA / MPFI e TC / FDI (Figura 16).

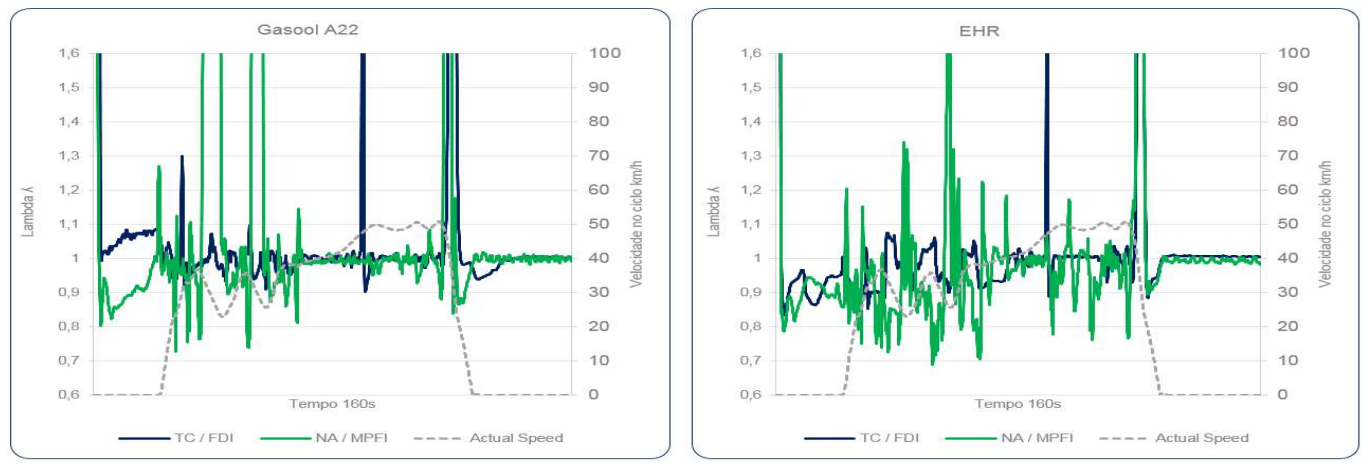

FIGURA 16- Relação estequiométrica TC / FDI e NA / MPFI nos combustíveis A22 e EHR

Destaca-se que a mistura, tanto no A22 e quanto no EHR, é mais controlada no veículo TC / FDI. Já no veículo NA / MPFI a mistura apresentou-se mais sensível as variações durante o ciclo. A maior estabilidade na mistura favorece à uma melhor otimização do catalisador. 


\subsection{ANALISE DA EFICIENCIA ENERGÉTICA}

Através do ensaio NBR 7024 determina-se a eficiência média energética, para atendimento ao programa nacional da racionalização do uso dos derivados do petróleo e gás natural.

A figura 17 apresenta os resultados de eficiência energética para os dois veículos estudados.

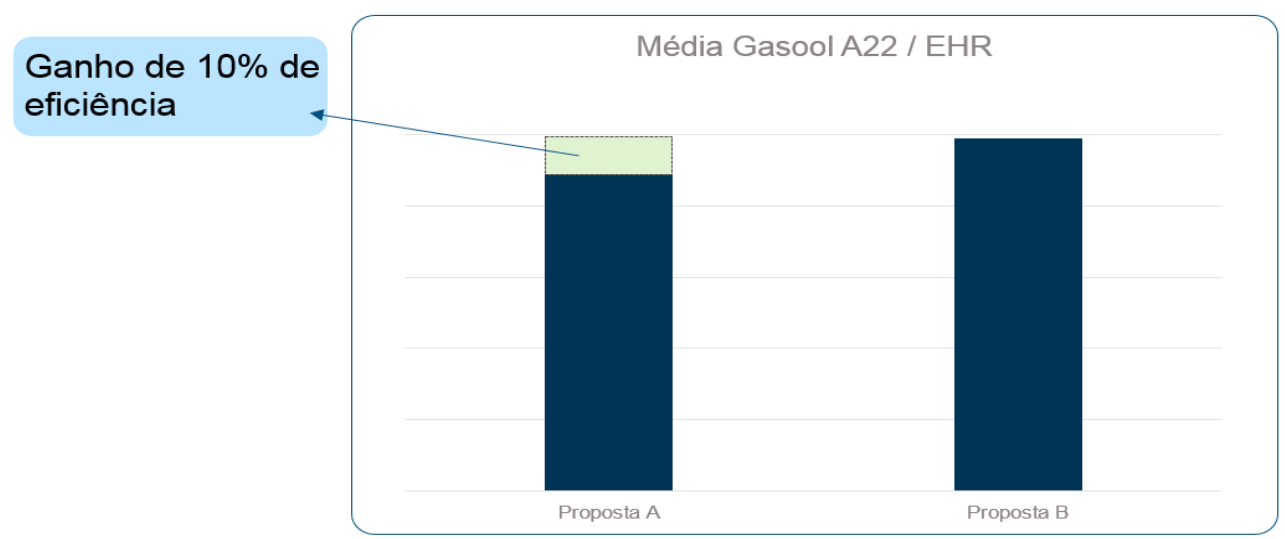

FIGURA 17 - Eficiência energética nos motores NA/MPFI e TC/FDI alimentados com A22 e EHR

O veículo com TC / FDI apresentou uma eficiência $10 \%$ superior ao veículo NA / MPFI. Essa maior eficiência energética também foi evidenciada pela temperatura menor no gás de escapamento desse veículo.

\section{CONCLUSÃO}

Com o trabalho, conclui-se que com a implementação de novas soluções tecnológicas nos motores Otto é necessário o desenvolvimento criterioso para uma solução catalítica.

O melhor controle de mistura ar / combustível e o perfil de temperatura mais estável observados no motor TC / FDI podem favorecer a uma maior durabilidade do catalisador.

Tecnologia TC / FDI demonstram um ganho em eficiência energética reduzindo a temperatura do gás de escapamento, requerendo soluções especificas de catalisador.

\section{REFERÊNCIAS}

[1] HECK, R.M.; FARRAUTO, R.J. Catalytic Air Pollution Control: Commercial Technology, Van Nostrand Reinhold, New York, 1995.

[2] BOSCH, Robert; Manual de Tecnologia Automotiva. São Paulo: Suely Blücher, 2005. 
[3] BRUNETTI, Franco; Motores de Combustão Interna: volume 1. São Paulo: Blücher, 2012.

[4] GRIFFITHS, J.F. Flame and Combustion.3. ed. London: Blackie Academic and professional, 1995.

[5] VAN WYLEN, Gordon John. Fundamentos da Termodinâmica clássica. 2. ed. São Paulo: Edgard Blücher, 1976.

[6] CIOLA, Remolo. Fundamentos da Catálise. 1. ed. São Paulo: Moderna, 1981.

[7] ABNT NBR 6601. Veículos rodoviários automotores leves - Determinação de hidrocarbonetos, monóxido de carbono, óxidos de nitrogênio, dióxido de carbono e material particulado no gás de escapamento. 3. ed. Rio de Janeiro: ABNT, 2012. 